\title{
PRESERVASI, KONSERVASI DAN RENOVASI KAWASAN KOTA TUA JAKARTA
}

\author{
Budi Setiawan \\ Jurusan Desain Interior, Fakultas Komunikasi dan Multimedia, Universitas Bina Nusantara \\ Jln. K.H. Syahdan No.9, Palmerah, Jakarta Barat 11480 \\ bsetiawan@binus.edu
}

\begin{abstract}
"Great nation is a nation who's always appreciates their own history," that was a statement from Bung Karno. This paper is trying to lift a heritage district in Kota Tua Jakarta. A legacy that full of arts, cultures, stories, romance and tragedy that happened, and how the origin of the city formed. It's very unfortunate if you see the condition right now. When all of the nations soo proud of their culture and history, everyone is competing to maintain and conserve their heritage and run the management very well. What happened with our heritage? Nowadays, Kota Tua district has been revitalized, but sadly, the process didn't maintained well. So the results looks neglected and not in the good shape.
\end{abstract}

Keywords: Jakarta Kota Tua district, heritage, revitalization

\begin{abstract}
ABSTRAK
"Bangsa yang besar adalah bangsa yang menghargai sejarah bangsanya," begitu kira-kira yang pernah disebutkan oleh Bung Karno. Tulisan ini ingin mengangkat peninggalan sejarah yang berada di kawasan Kota Tua Jakarta. Sebuah peninggalan sejarah yang sarat akan konten seni, budaya, cerita, romantisme dan tragedi yang terjadi, serta bagaimana asal mula kota Jakarta terbentuk. Teramat sangat disayangkan jika melihat keadaannya sekarang. Dimana saat ini bangsa lain begitu menghargai kebudayaan dan sejarah yang mereka miliki, semua berlomba memelihara dan melestarikan warisan terpenting mereka dan mengelolanya dengan baik. Apa yang terjadi dengan warisan yang kita miliki? Saat ini kawasan Kota Tua di Jakarta memang dalam tahap revitalisasi, tapi yang menyedihkan, tidak dijaga dan dikelola dengan baik. Sehingga revitalisasi yang sedang berjalan (walaupun tersendat-sendat) menjadi terbengkalai dan tampak semrawut.
\end{abstract}

Kata kunci: kawasan Kota Tua Jakarta, peninggalan sejarah, revitalisasi 


\section{PENDAHULUAN}

Wisata peninggalan sejarah (urban heritage tourism) kini semakin mendapat tempat di hati wisatawan. Budaya selalu menjadi obyek wisata utama diseantero dunia. Namun sekitar tiga dasawarsa lalu, tren wisata budaya mulai terpecah, wisatawan mulai tertarik juga pada hasil peninggalan masa lampau yang menempel pada dinding-dinding bangunan dikota bersejarah pada setiap negara yang mereka kunjungi.

Heritage, atau warisan berupa berbagai peninggalan dalam segala bentuk, penting bukan hanya sebagai sebuah identitas kota dan negara tapi juga bernilai ekonomi serta memberi dampak sosial. Budaya merekatkan manusia untuk mencipta saling pengertian yang membawa pada kedamaian dan keharmonisan. Wisata heritage pada akhirnya juga membantu memelihara dan melestarikan heritage/ warisan itu sendiri.

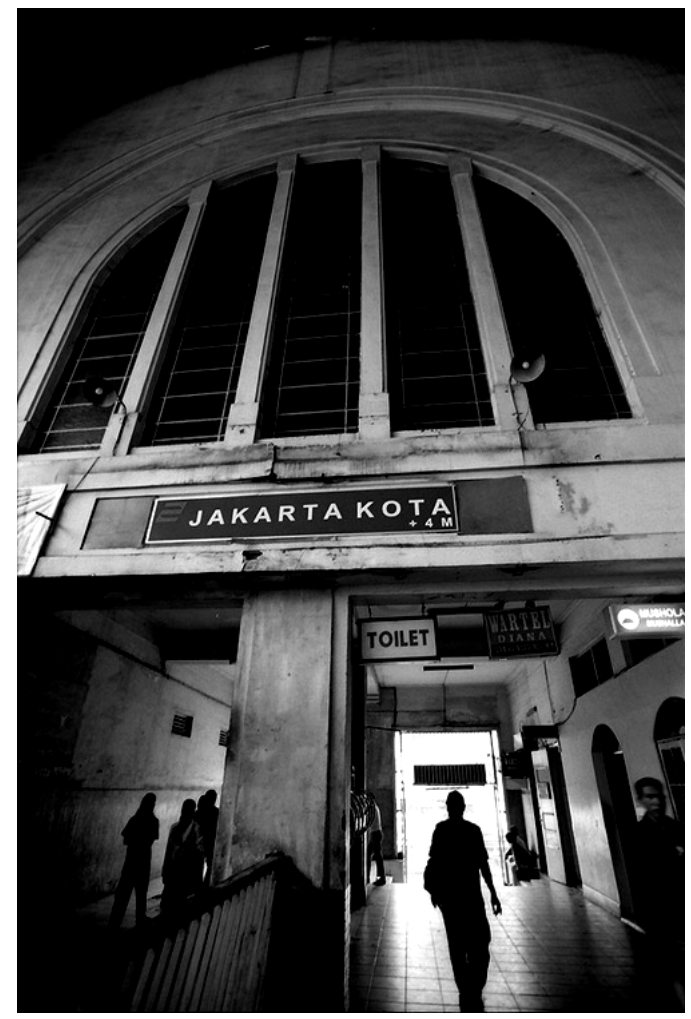

Gambar 1 Stasiun Kota

\section{PEMBAHASAN}

Aktivitas pemeliharaan bangunan tidak sekedar merupakan kegiatan merawat bangunan secara fisik saja melainkan merupakan kegiatan yang mencakup aspek teknis maupun administratif dalam mempertahankan dan memulihkan fungsi bangunan sebagaimana mestinya. Masalah yang pada umumnya muncul dalam pemeliharaan bangunan adalah terkait dengan nilai kesejarahan baik arsitektural, kota maupun budaya sebuah bangsa yang harus dihadapkan terhadap beberapa tuntutan fungsi, teknis dan performansi bangunan maupun perundangan dan bahkan kepemilikannya. 


\section{Pemeliharaan Bangunan}

Maintenance atau pemeliharaan pada bangunan dimaksudkan sebagai gabungan dari tindakan teknis dan administratif yang dimaksudkan untuk mempertahankan, dan memulihkan fungsi bangunan sebagai mana yang telah direncanakan sebelumnya. Keberhasilan suatu bangunan dinilai dari kemampuan bangunan untuk ada pada kondisi yang diharapkan, yang dipengaruhi oleh beberapa persyaratan, antara lain: (1) persyaratan fungsional, yaitu persyaratan yang terkait dengan fungsi bangunan. Setiap bangunan memiliki persyaratan fungsional umum dan khusus yang perlu dipenuhi; (2) persyaratan performance, masing-masing bangunan memiliki persyaratan performance bangunan yang sangat spesifik. Performance bangunan mencakup banyak aspek, mulai dari performance fisik luar bangunan, sampai pada elemen-elemen Mechanical \& Electrical (ME). Tindakan pemeliharaan bangunan sangat ditentukan oleh tuntutan performance yang terkait dengan fungsi bangunan; (3) persyaratan menurut Undang-undang, merupakan persyaratan bangunan yang tidak bisa diabaikan, karena menyangkut regulasi dan legalitas; (4) persyaratan menurut user, biasanya berkaitan dengan kenyamanan. Kenyamanan user merupakan ukuran keberhasilan suatu bangunan. Biasanya bangunan yang memiliki persyaratan user adalah bangunan-bangunan sewa dan bangunan-bangunan umum.

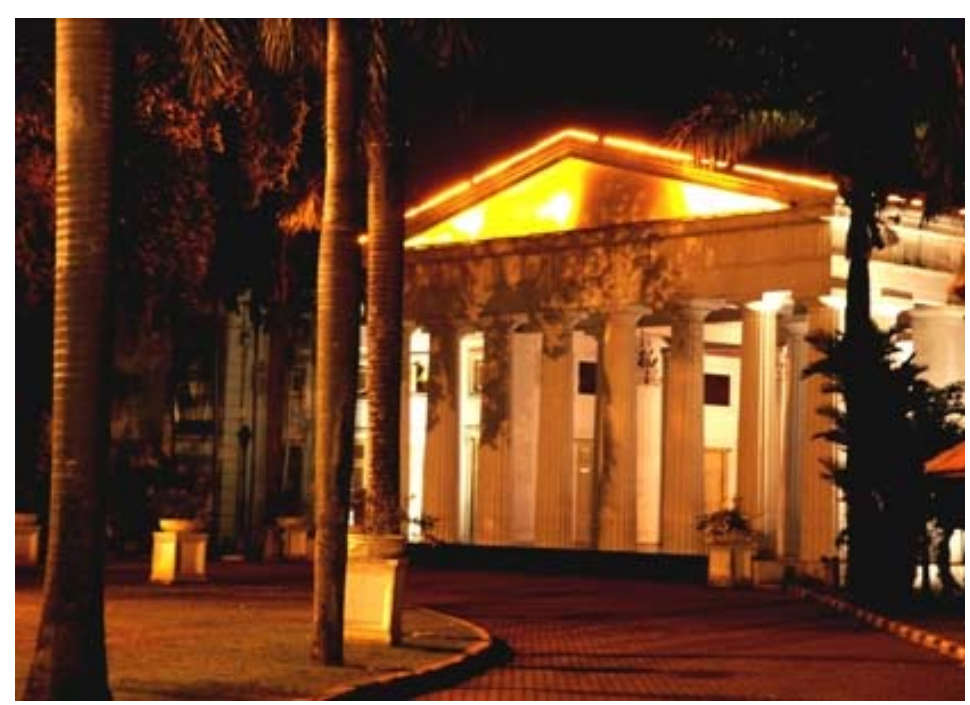

Gambar 2 Tampak depan Museum Keramik pada malam hari

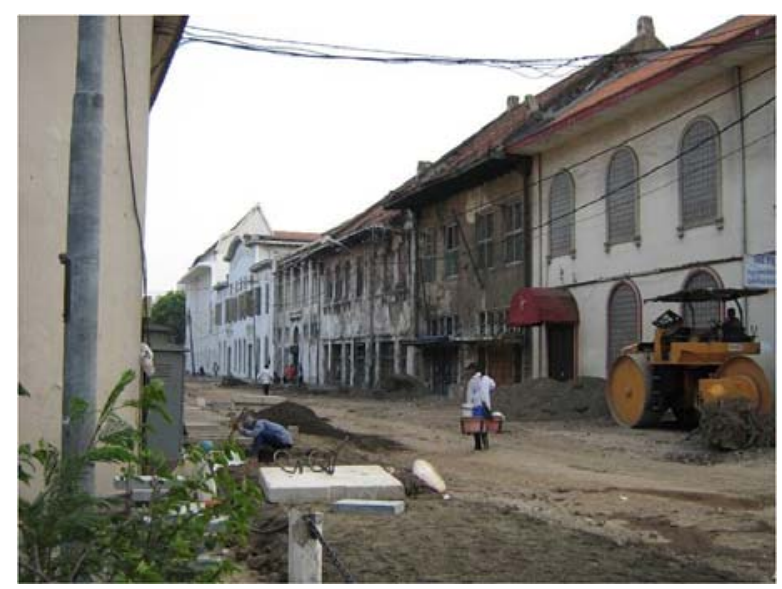

Gambar.3 Proses pemugaran kawasan Kota Tua 


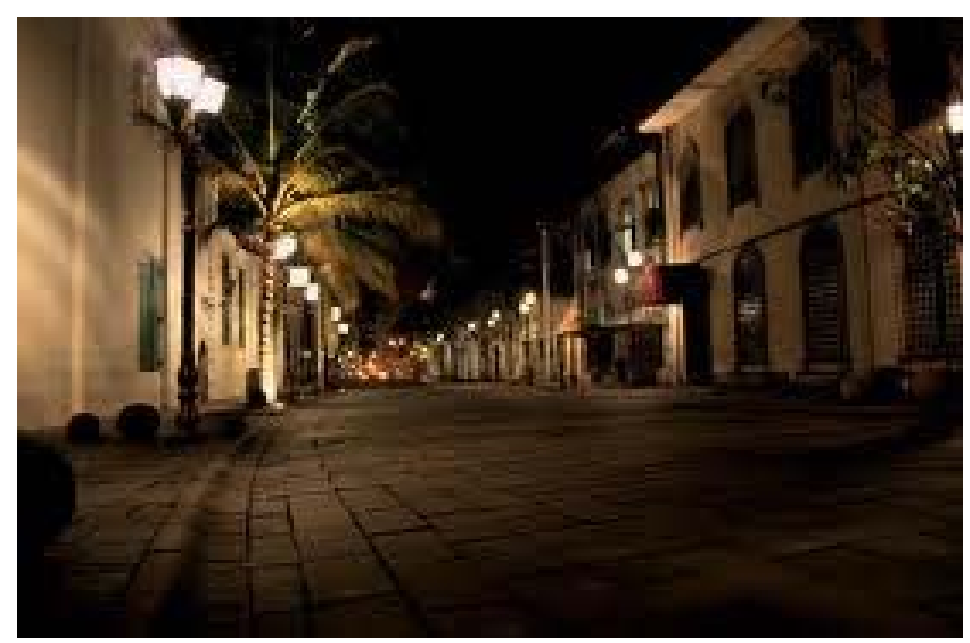

Gambar 4 Proses Pemugaran Kawasan Kota Tua

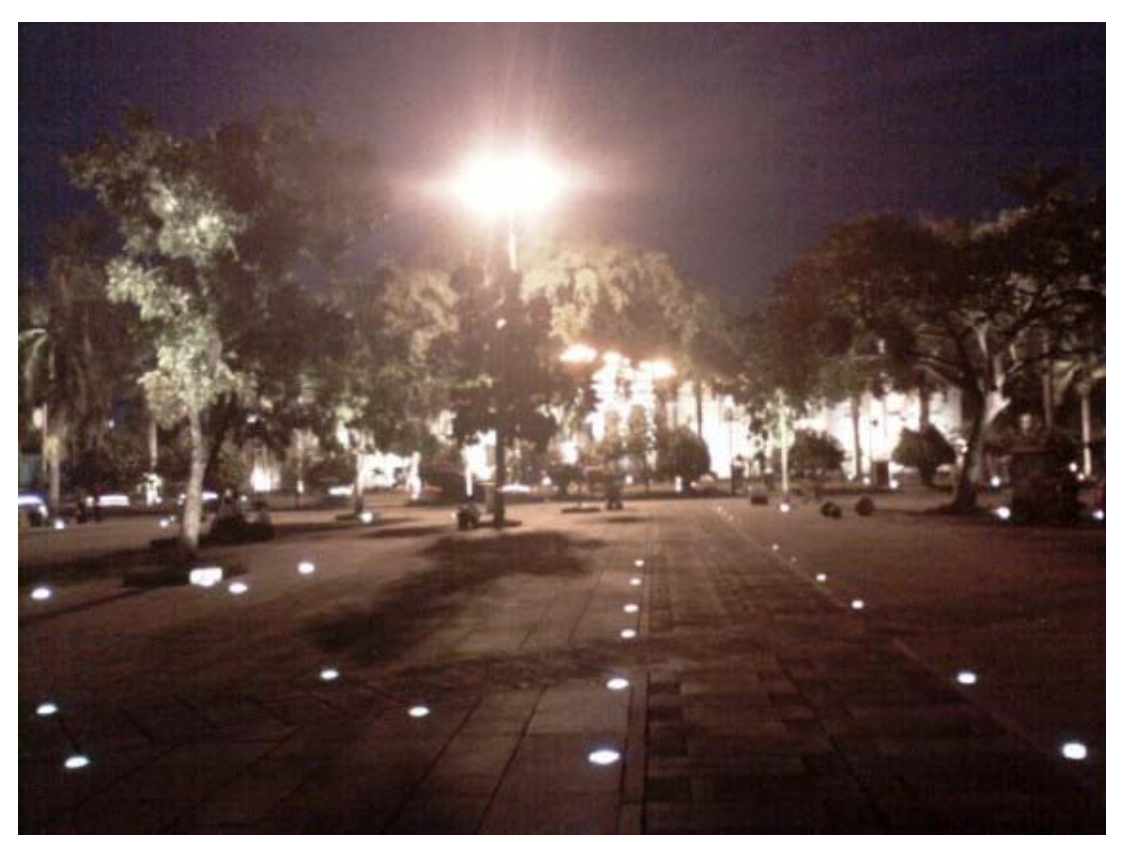

Gambar 5 Halaman Depan Museum Sejarah Jakarta pada Malam Hari

Idealnya, pada tahap desain, perencana telah menyusun kriteria-kriteria untuk menghasilkan suatu performansi tertentu sehingga aktifitas pemeliharaan yang dilakukan selama masa operasi gedung akan lebih efektif. Namun seringkali kriteria-kriteria semacam itu tidak dibuat sehingga menimbulkan kesulitan dalam menentukan program pemeliharaan sampai tahap pelaksanaannya.

Kegiatan pemeliharaan bangunan meliputi berbagai aspek yang bisa dikategorikan dalam 4 kegiatan, yaitu pemeliharan rutin harian, rectification (perbaikan bangunan yang baru saja selesai), replacement (penggantian bagian yang berharga dari bangunan), dan retrofitting (melengkapi bangunan sesuai kemajuan teknologi). Poin-poin ini adalah aspek teoritis yang jika dijalankan dengan benar, maka proses pemeliharaan dapat berjalan dengan sempurna. Tapi selain aspek tersebut diatas, masih ada aspek yang menentukan progress pemeliharaan yang akan dilakukan, yaitu aspek budaya dan etika. 


\section{Pemeliharaan yang terkait Aspek Budaya dan Etika}

Saat ini kawasan Kota Tua sudah dalam tahap revitalisasi. Presiden RI pun mencanangkan tahun 2010 sebagai tahun kunjungan museum dan pariwisata sejarah. Tetapi apa yang terjadi dengan perjalanan proses revitalisasi ini? Setelah mendapati kondisi bangunan bersejarah bagi kota Jakarta ini sedemikian memprihatinkan, penulis ingin mengingatkan kembali pada acuan dasar pelestarian sebuah benda atau kawasan bersejarah yang tentunya disusun sendiri oleh pemerintah.

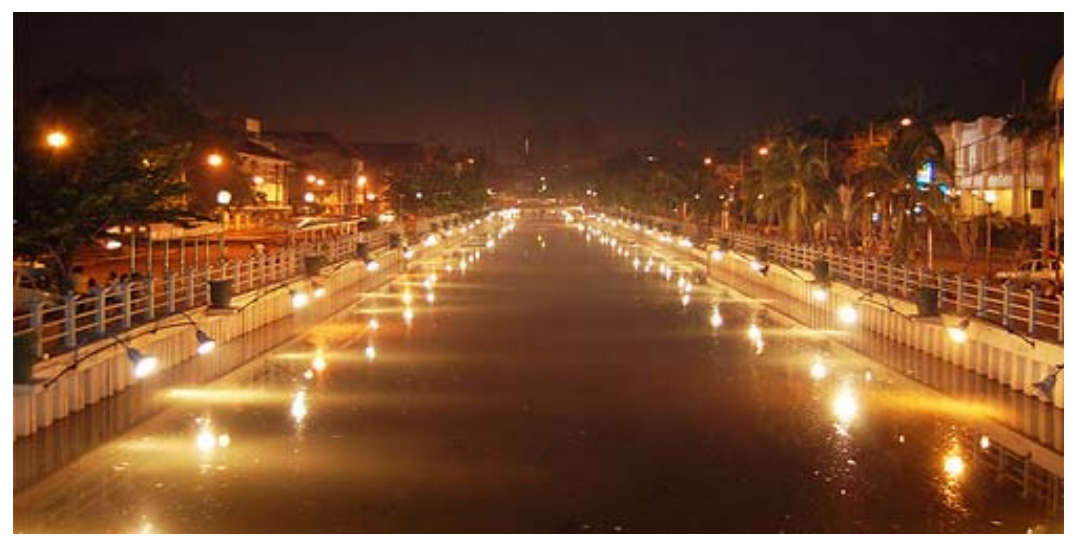

Gambar 6 Kanal Air Batavia Pada Malam Hari

Pelestarian sebuah benda atau bangunan bersejarah memiliki acuan hukum, yaitu (1) Undangundang RI Nomor 5 Tahun 1992 tentang Benda Cagar Budaya; (2) Peraturan Pemerintah Nomor 10 Tahun 1993 tentang Pelaksanaan Undang-undang RI Nomor 5 Tahun 1992; (3) Peraturan Pemerintah Nomor 19 Tahun 1995 tentang Pemeliharaan dan Pemanfaatan Benda Cagar Budaya; (4) Keputusan Menteri Kebudayaan dan Pariwisata Nomor KM.33/PL.303/MKP/2004 tentang Museum dan benda bersejarah.

Pemerintah menyusun UU yang mengatur benda cagar budaya, pelaksanaanya, pemeliharaan dan pemanfaatannya dan masih banyak lagi. Tapi apa gunanya kawasan ini direvitalisasi, kemudian tidak dirawat? Mengintip ke negara tetangga Indonesia, Malaysia, ada Malaka yang tahun lalu masuk dalam daftar World Heritage Sites. Lalu Singapura. Intinya, semua berlomba memelihara dan melestarikan warisan terpenting mereka sekaligus mengelolanya dengan baik. Pada akhirnya memang, nilai ekonomi heritage begitu terasa langsung bagi kota dan penduduknya. Kafe, restoran, hotel, toko suvenir, pedagang tradisional semua terkena dampak berputarnya uang. Selain itu, keberlangsungan sebuah kota -lengkap dengan peninggalan sejarah dan budaya- terjaga bagi generasi selanjutnya.

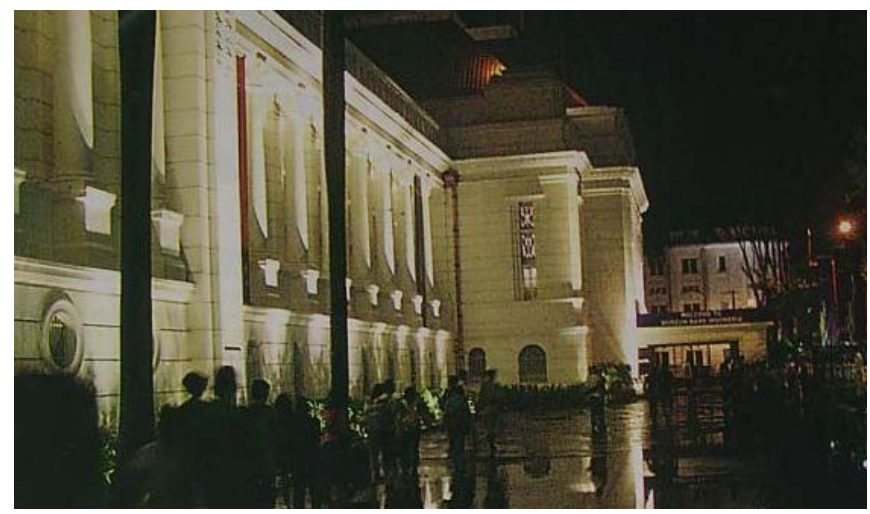

Gambar 7 Gedung Museum Bank Indonesia 


\section{PENUTUP}

Lantas, bagaimana dengan Jakarta? Di usia yang menjelang 500 tahun, dalam rentang waktu yang kurang dari 20 tahun ke depan, Jakarta masih saja berantakan. Sudahkah Jakarta menciptakan citranya sebagaimana kota-kota lain di dekatnya? Kawasan bersejarah Jakarta yang sedang dalam proses dihidupkan kembali kini terkesan tidak berjalan sesuai rencana. Macet bukan hanya karena masalah pembangunan fisik, dan pembenahan ulang -karena dalam waktu dua tahun sudah babak belur lagi sehingga harus tambal sulam- tapi juga karena tak jelas arah revitalisasi itu. Terlalu banyak kepentingan, sudah cukup banyak ahli-ahli yang peduli akan hal ini, tetapi tidak ditanggapi dengan serius oleh pemerintah.

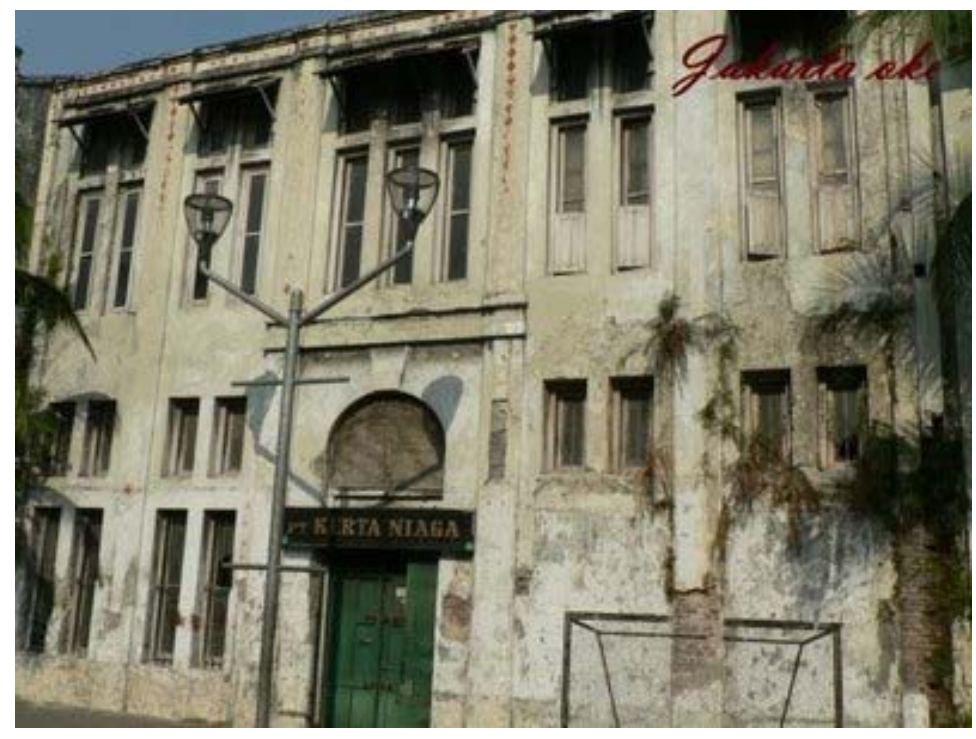

Gambar 8 Salah Satu Bangunan yang Mulai Hancur

\section{DAFTAR PUSTAKA}

Dinas Museum dan Pemugaran DKI Jakarta. (1999). Himpunan Peraturan Permuseuman Pemerintah DKI Jakarta.

Dinas Pariwisata Daerah DKI Jakarta. (2005). Draft Rencana Induk Pengembangan Pariwisata Daerah DKI Jakarta.

Dundu dan Elita, P. (2005). ”30 Tahun Revitalisasi Kota Tua Cuma Sebatas Konsep”. Kompas (Jakarta).

Orbasli, A. (2000). Tourist in Historic Towns: Urban Conservations and Heritage Management. London: E \& FN Spon.

Yale, P. (1991). From Tourist Attraction in Heritage Tourism. 